Case Study

\title{
Physical therapy prehabilitation on a reverse total shoulder replacement candidate: a case study
}

\author{
JAMES F. Villers, PT, DPT, FAAOMPT ${ }^{1)}$, JACOB BURCH, PT, DPT ${ }^{1)}$, \\ Mark Scheller, PT, DPT ${ }^{1)}$, Han-Hung Huang, PT, PhD ${ }^{1)^{*}}$
}

1) Department of Physical Therapy, Angelo State University: ASU Station No. 10923, San Angelo, TX 76909-0923, USA

\begin{abstract}
Purpose] The purpose of this report is to describe the PT evaluation, prehab interventions, and outcomes of a patient pursuing reverse total shoulder replacement (rTSR) for pain reduction and functional gains. [Participant and Methods] A 62-year-old male self-referred to PT two months before his right rTSR. His chief complaints were right shoulder pain, stiffness, and functional impairment due to rotator cuff tendon tears and shoulder arthritis. He demonstrated poor posture, limited ROM, decreased strength, and diminished function. The PT prehab program consisted of an initial encounter followed by six treatment sessions across approximately one month. [Results] On the last visit, the patient's pain had meaningfully decreased along with improved posture, AROM, and muscle strength producing a clinically significant improvement in function resulting in the postponing of his rTSR. On a three months follow-up, the patient had maintained or improved in his test and measures and functional outcomes. He expressed satisfaction with the prehab outcomes and that he had indefinitely postponed his rTSR. [Conclusion] PT prehab program improved pre-operative measures on pain, posture, joint mobility, muscle strength, and function on a patient who had been scheduled for rTSR surgery. PT prehab program may delay the need for rTSR surgery. Key words: Physical therapy, Prehabilitation, Total shoulder replacement
\end{abstract}

(This article was submitted Oct. 3, 2019, and was accepted Nov. 28, 2019)

\section{INTRODUCTION}

Prehabilitation (prehab) or preoperative rehabilitation is the process of physical, psychological, or nutritional intervention for patients in anticipation of surgical procedures ${ }^{1)}$. The central premise is that optimizing patients' wellness to prepare them for surgery and to expedite the recovery after surgery ${ }^{2}$. Prehab may also decrease post-surgical complication rates, shorten the length of hospital stay, reduce costs of healthcare, and improve patient perceived health-related quality of life $\mathrm{e}^{3-5)}$. Prehab has been applied to several surgical populations including cardiopulmonary, abdominal, oncology, and orthopedic surgeries ${ }^{4,6-11)}$.

Physical therapy (PT) prehab has promising benefits to patients undergoing orthopedic surgeries. Existing evidence suggests that preoperative exercise training reduces length of stay and improves pain and functional outcomes on patients undergoing total hip or knee arthroplasty and anterior cruciate ligament (ACL) reconstruction ${ }^{12-14}$ ). In addition, one systematic review found that prehab intervention reduced the total cost of healthcare spending associated with spinal surgery ${ }^{3}$.

The use of total shoulder replacement (TSR) has doubled in the last decade with up to 70,000 surgeries performed annually in the United States of which one-third are reverse TSR (rTSR) ${ }^{15-17)}$. The reversed articular surfaces allows the deltoid muscle to become a primary elevator of the shoulder, thus, making it suited for individuals with advanced osteoarthritis (OA) and massive rotator cuff tears ${ }^{18)}$. There is no published research documenting the use of prehab in individuals electing for

*Corresponding author. Han-Hung Huang (E-mail: floyd.huang@angelo.edu) (Supplementary material: refer to PMC https:// www.ncbi.nlm.nih.gov/pmc/journals/2193/) 
rTSR. Therefore, the purpose of this case study is to describe the PT evaluation, prehab interventions, and outcomes of a patient pursuing rTSR for pain reduction and functional gains. The findings of this study may trigger future investigations in the benefits of prehab in an rTSR population.

\section{PARTICIPANT AND METHODS}

The patient of this case study provided written informed consent to Angelo State University for the examination, intervention, and publication of the results. The patient was a 62-year-old, left handed, Caucasian male employed as a university professor. His primary MRI diagnoses in the right shoulder were complete tears with retraction of the supraspinatus, infraspinatus and long head of the biceps; partial tear of the subscapularis; tear of the anterior labrum, subacrominal bursitis, glenoid chondromalacia; and hypertrophic changes of the acromioclavicular joint with narrowing of the subacromial space. Based on the MRI findings and clinical examination, his orthopedic surgeon recommended an rTSR. The patient self-referred approximately two months prior to the scheduled surgery date expressing an interest in prehab.

The patient sustained initial injury to the right shoulder 20 years ago, but did not seek medical attention or treatment. Since the onset, he described transient pain with overuse of the right shoulder. Six months prior to the PT visit, the patient suffered traumatic damage to the right shoulder when he attempted to lift and flip a heavy object. He had immediate onset of intense pain with the inability to lift his right arm. A few days later, he developed a large area of ecchymosis in the right upper medial arm. Medical attention was sought at an urgent care clinic eight weeks after the incident. The evaluating family nurse practitioner ordered a MRI and referred him to his current orthopedic surgeon.

During the prehab initial evaluation, the patient's chief complaint was sharp pain in the right shoulder with overhead activities, especially with the addition of weight. He also reported painful donning/doffing of upper body clothing, lifting larger pots and pans, and sleeping on his right side. In the morning, he experienced pain and stiffness which resolved by the afternoon. In general, resting the shoulder in a neutral position relieved his symptoms and over the counter non-steroidal anti-inflammatory medication would aid in sleeping.

The patient's past medical and surgical history were reviewed and found to be noncontributory to his current chief complaint nor limiting to his prehab participation. The patient's stated goals were: 1) pain control, 2) increase active mobility, 3) regain ability to play golf, and 4) use of a mechanical drill for wood working or home improvements.

The PT initial evaluation was focused on the mobility, stability, and strength of the shoulder complex (glenohumeral/ scapulothoracic joints), cervicothoracic junction (CTJ), and thoracic spine. Prior to the physical examination, functional outcome measures were recorded for pain and the function of the right shoulder and upper limb.

The functional outcome assessments (Table 1) consisted of: Numeric Pain Rating Scale (NPRS), Shoulder Pain and Disability Index (SPADI), and Quick Disability of Arm, Shoulder, and Hand (QuickDASH). The NPRS is a reliable and valid instrument for scoring pain ${ }^{19)}$. The patient is requested to select a whole number that best reflects his or her pain on an 11-point numeric scale with the anchors 0 no pain and 10 worst pain imaginable. Pain was rated in four categories: 1) current, 2) usual pain during the last week, 3) best level of pain during the last week, and 4) worst pain during the last week. The patient scored his current and pain at best $0 / 10$ and pain at worst 8/10. In a shoulder pain population, a 2-point reduction represents the minimally clinically important difference (MCID) $)^{20)}$. The SPADI is joint specific measure focusing on pain and functional activities involving the shoulder ${ }^{21)}$. It has been shown to be valid and reliable, as well as responsive to change and able to differentiate patients who are improving or worsening ${ }^{22,23)}$. SPADI scores range from $0 \%$ to $100 \%$ with higher scores designating greater disability. Three categories are scored on the SPADI: pain, disability, and total. The patient recorded a pain score of $46 \%$, disability $30 \%$, and total $36 \%$. The minimal detectable change (MDC) ranges from 18.1 to $21.5 .{ }^{24,25}$ ) The MCID ranges from 13.2 to $15.4^{24,26)}$. The QuickDASH is an upper extremity, region specific self-reported outcome measure that assesses areas such as functional mobility, life participation, and social functioning. A strong correlation has been reported between the DASH and QuickDASH, but QuickDASH is preferred in order to reduce patient burden ${ }^{27-29)}$. Disability is rated from $0 \%$ to $100 \%$ with higher scores indicating greater functional limitations. A disability of $61 \%$ was reported by the patient. The MDC for QuickDASH range from 11 to 17.18 , and MCID range from 9.0-11.330,31).

Upon observation (Table 2), there was visible atrophy in the right infraspinatus, supraspinatus, and teres minor as compared to left side. The patient demonstrated an "upper-crossed" posture: forward head, rounded shoulders, and thoracic kyphosis ${ }^{32)}$. The right scapula was minimally elevated at rest with the superior angle positioned between T1 and T2. The scapulae were slightly abducted, 3.25 inches vertebral border from spine. No evidence of scapular upward or downward rotation was identified. Assessment of the patient's pectoralis minor (Pm) and deep neck flexors (DNF) were performed secondary to his upper crossed posture. Pm length was measured per previously described methods ${ }^{33)}$. The length measurement results were 4 inches on the right and 3.25 inches on the left. These results indicated bilateral Pm muscles tightness based on the norm of $1 \mathrm{inch}^{33)}$. To assess the performance of the DNF, endurance testing was completed per Domenech et al ${ }^{34)}$. The result on the DNF endurance test was 8.79 seconds and the norm for males is suggested as 38.9 seconds $^{34)}$. These results indicated an impaired flexibility of Pms and poor endurance of DNF, which could be associated with patient's poor posture.

The mobility of CTJ and thoracic spine were assessed as a possible contributing source of shoulder pain. Passive accessory intervertebral movement (PAIVM) assessment in a posterior to anterior (PA) direction indicated hypomobility throughout the thoracic spine with severe limitations at the CTJ. The restricted PAIVM PA findings were consistent with the observed 
Table 1. Functional outcome measures

\begin{tabular}{lllll}
\hline Measures & Initial evaluation (Day 1) & Fifth visit (Day 18) & Final evaluation (Day 32) & Three months follow-up \\
\hline NPRS & Right now: 0 & Not scored & Right now: 0 & Right now: 0 \\
& Usual pain over last week: & Usual pain over last & Usual pain over last \\
& Not recorded & week: 0 & week: 1 \\
& Pain at best: 0 & & Pain at best: 0 & Pain at best: 0 \\
& Pain at worst: 8 & & Pain at worst: 8 & Pain at worst: 4 \\
SPADI & Pain: $46.0 \%$ & Pain: $52.0 \%$ & Pain: $34.0 \%$ & Pain: $20.0 \%$ \\
& Disability: $30.0 \%$ & Disability: $20.0 \%$ & Disability: $12.5 \%$ & Disability: $3.75 \%$ \\
& Total: $36.0 \%$ & Total: $32.0 \%$ & Total: $20.8 \%$ & Total: $18.2 \%$ \\
QuickDASH & Total: $61.0 \%$ & Total: $36.0 \%$ & Total: $29.5 \%$ & Total: $27.2 \%$ \\
\hline
\end{tabular}

Table 2. Postural tests and measures

\begin{tabular}{llll}
\hline Test & Initial evaluation (day 1) & Final evaluation (day 32) & Three months follow-up \\
\hline Distance from medial border & R: 3.25 inches & R: 3.0 inches & R: 3.0 inches \\
of scapula to spine & L: 3.25 inches & L: 3.0 inches & L: 3.0 inches \\
Scapular positioning & R: $1 / 2$ segment high & R: $1 / 2$ segment high & R: $1 / 2$ segment high \\
& L: $1 / 2$ segment high & L: $1 / 2$ segment high & L: $1 / 2$ segment high \\
Pec Minor tightness test & R: 4.0 inches & R: 3.0 inches & R: 3.5 inches \\
& L: 3.25 inches & L: 2.75 inches & L: 2.75 inches \\
DNF endurance test & 8.79 seconds & 16.80 seconds & 15.05 seconds \\
\hline
\end{tabular}

DNF: Deep neck flexors.

Table 3. Active range of motion

\begin{tabular}{llccc}
\hline $\begin{array}{l}\text { Movement } \\
\text { R GHJ }\end{array}$ & Initial evaluation (day 1) & $\begin{array}{c}\text { Second visit } \\
\text { (day 4) }\end{array}$ & $\begin{array}{c}\text { Final evaluation } \\
\text { (day 32) }\end{array}$ & $\begin{array}{c}\text { Three months } \\
\text { follow-up }\end{array}$ \\
\hline Flexion & $60^{\circ}$ (with onset of 4/10 pain) & $150^{\circ}$ & $163^{\circ}(0 / 10$ pain) & $166^{\circ}(0 / 10$ pain) \\
Abduction & $75^{\circ}$ (with onset of $1 / 10$ pain) & $153^{\circ}$ & $168^{\circ}(0 / 10$ pain) & $180^{\circ}(0 / 10$ pain) \\
Extension (standing) & $63^{\circ}$ & $63^{\circ}$ & $77^{\circ}(0 / 10$ pain) & $75^{\circ}(0 / 10$ pain $)$ \\
External rotation (scapular plane) & $68^{\circ}$ & $62^{\circ}$ & $66^{\circ}(0 / 10$ pain) & $77^{\circ}(0 / 10$ pain $)$ \\
Internal rotation (scapular plane) & $50^{\circ}$ & $67^{\circ}$ & $72^{\circ}(0 / 10$ pain) & $75^{\circ}(0 / 10$ pain $)$ \\
Horizontal adduction & $23^{\circ}$ & Not measured & $45^{\circ}(1 / 10$ pain $)$ & $43^{\circ}(0 / 10$ pain $)$ \\
Scapular upward rotation during flexion & $45^{\circ}$ & Not measured & $55^{\circ}$ & $58^{\circ}$ \\
\hline
\end{tabular}

R GHJ: Right glenohumeral joint.

kyphotic posture.

Glenohumeral joint (GHJ) active range of motion (AROM) was measured by a standard gonimeter per Norkin and White $(\text { Table } 3)^{35)}$. The patient was significantly limited in all planes. When performing shoulder flexion at 60 degrees, pain was reported to be $4 / 10$ on the NPRS. The patient reported at times during overhead reach pain could increase to 8/10. At 75 degrees of shoulder abduction, pain was rated at 1/10. All other movements were pain free. During active elevation, a deficit in right scapula upward rotation was noted. Forty five degrees was recorded with measuring the vertebral border of the scapula to a vertical axis, lacking 15 degrees from the normal of 60 degrees ${ }^{36)}$.

Right GHJ passive range of motion (PROM) was assessed in a supine position. PROM was found to be normal in all planes except internal rotation (IR) were 60 degrees was noted. Passive accessory motion (PAM) testing in an anterior to posterior (AP) glide confirmed the IR limitation a mild capsular end feel. Patient denied any production of pain with PROM testing. With AROM and PROM, there was palpable crepitus noted in the right GHJ throughout movements.

Strength tests (Table 4) were performed via manual muscle testing on selected scapulo-humeral and scapulo-thoracic muscles ${ }^{37)}$. Overall, the patient demonstrated decreased muscle strength on the right when compared to his left upper extremity. Pain and rotator cuff pathology was a limiting factor in the performance of the scapulo-humeral muscles with flexion, abduction, and ER. Weakness of the scapulo-thoracic stabilizers was consistent with the scapular upward rotation deficit and upper cross syndrome posture.

To clinically confirm the MRI findings, the following special tests were completed. The rent test was found to be positive 
Table 4. Manual muscle tests

\begin{tabular}{lccc}
\hline Muscles & Initial evaluation (day 1) & Final evaluation (day 32) & Three months follow-up \\
\hline R middle trap & $3-/ 5$ & $4+/ 5$ & $5 / 5$ \\
R internal rotation & $4 / 5$ & $4 / 5$ & $4+/ 5$ \\
R external rotation & $3+/ 5$ & $3+/ 5$ & $3+/ 5$ (pain reproduced) \\
R lower trap & $3+/ 5$ & $4 / 5$ & $4+/ 5$ \\
R serratus anterior & $3+/ 5$ & $5 / 5$ & $5 / 5$ \\
R shoulder flexion & $2+/ 5$ & $4+/ 5$ (pain reproduced) & $5 / 5$ \\
R shoulder abduction & $3+/ 5$ & $4+/ 5$ & $4+/ 5$ \\
\hline
\end{tabular}

suggesting a rotator cuff tear (SP 97, +LR 32) ${ }^{38)}$. The lack of integrity of the supraspinatus and infraspinatus were confirmed by weakness and pain during the external rotation lag sign (SP 90, +LR 4.20) ${ }^{39}$. Labrum pathology and glenoid chondromalacia were suggested during completion of a crank test (pooled SP 75) with detected crepitus and clicking ${ }^{40)}$. Biceps load I testing (SN 97) was negative for labrum pain ${ }^{41}$. It was reasoned that, the full tear with retraction of the long head of the biceps failed to provide tension on the labrum resulting in the negative test.

The prehab program consisted of an initial encounter (evaluation and treatment) followed by six treatment sessions spread across 32 days. The impairment-based interventions were developed based on the findings during the initial evaluation and the patient's responses during each subsequent visit. Six therapeutic exercises were prescribed to the patient as his home exercise program (HEP). The specific exercise prescription during each session is summarized in Table 5. Please refer to supplementary document for detailed instructions.

(1) Supine on towel roll with sequential setting of transversus abdominis (TA), DNF, and scapular retractors for a 5 second hold (Fig. 1). The purpose of this exercise was to address the physical impairments that were contributing to his postural abnormalities, thus promoting normal scapular resting positioning.

(2) Y's on a wall (Fig. 2): at the end range of elevation, scapular upward rotation was emphasized by completing a shoulder shrug and then moving hands from the wall by scapular retraction. This exercise focused on establishing normal scapulohumeral rhythm.

(3) GH internal rotation (IR) and external rotation (ER) in prone and standing. To insure pure rotation, the patient was cued to imagine a dowel was running through his elbow to his shoulder, thus only allowing a spinning motion at the shoulder. The goals of this exercise were to increase the strength and endurance of the rotator cuff muscles and scapular control by activating the lower trapezius during prone $\mathrm{ER}^{42}$.

(4) Prone Scapular Y's: the emphasis of this exercise was to increase the strength and endurance of the scapular stabilizers, specifically the lower trapezius.

(5) Scaption flys with elbow flexed to 90 degrees in front of a mirror (Fig. 3). With visual feedback provided by a mirror, the patient was instructed to only raise his arms as high as he could without compensatory right shoulder hiking. The function of this exercise was to retrain normal scapulohumeral rhythm and to strengthen GH elevators. To progress this exercise, the patient gradually extended his elbows while avoiding excessive elevation of the right scapula.

(6) Wax on/wax off on a horizontal surface (Fig. 4). By introducing compression through the GHJ, muscular co-contraction was enhanced leading to improved stability of the GHJ. To progress this exercise, the patient leaned further over the table, performed larger clockwise and counterclockwise circles, or a combination of those two methods.

During each treatment session, the patient reported how he had tolerated the HEP and if he had noted any changes in pain or function. As indicated, the patient was instructed on means to progress his exercises and on any new exercises. In order to determine his mastery of the HEP, he was asked to perform each assigned exercise. Patient compliance with the HEP was evaluated by considering the patient's ability to accurately describe and perform the exercises without assistance or cuing and self-reported compliance. He demonstrated excellent skill level with his HEP with a self-reported compliance rate $\geq 90 \%$ on his 4th and 6th visits.

Therapist delivered spinal mobilization (SM) was completed outside of the HEP. To improve CTJ and thoracic extension mobility, posterior to anterior (PA) mobilization was performed as part of the first and the third visits. SM was completed in prone and consisted of progressive PA oscillations from I-IV grades to the targeted segments. To further enhance thoracic mobility and produce neurophysiological pain reducing effects, the SM session was ended with a grade V impulse to the mid-thoracic region ${ }^{43)}$.

\section{RESULTS}

On the last visit of the program (Day 32), a reassessment was performed. The NPRS at worse continued to be as the baseline 8/10. While the patient did not have a reduction in his NPRS at worse, he reported complete relief of night pain and pain with usual daily activities. The patient's overall score on the SPADI decreased from $36.0 \%$ at baseline to $20.8 \%$ (Table 
Table 5. Home exercise program

\begin{tabular}{|c|c|c|c|c|c|c|c|}
\hline Exercise & Day 1 & Day 4 & Day 6 & Day 11 & Day 18 & Day 25 & Day 32 \\
\hline $\begin{array}{l}\text { Supine on towel roll } \\
\text { with TA activation, } \\
\text { DNF activation, and } \\
\text { scapular retraction }\end{array}$ & $\begin{array}{l}3 \text { sets of } 10 \\
\text { with a } 5 \\
\text { second hold } \\
2 \times \text { per day ** }\end{array}$ & $\begin{array}{l}3 \text { sets of } 10 \\
\text { with a } 5 \\
\text { second hold } \\
2 \times \text { per day }\end{array}$ & $\begin{array}{l}3 \text { sets of } 10 \\
\text { with a } 5 \\
\text { second hold } \\
2 \times \text { per day }\end{array}$ & $\begin{array}{l}3 \text { sets of } 10 \text { with } \\
\text { a } 5 \text { second hold } \\
2 \times \text { per day }\end{array}$ & $\begin{array}{l}3 \text { sets of } 10 \\
\text { with a } 5 \\
\text { second hold } \\
2 \times \text { per day }\end{array}$ & $\begin{array}{l}3 \text { sets of } 10 \text { with } \\
\text { a } 5 \text { second hold } \\
2 \times \text { per day }\end{array}$ & $\begin{array}{l}3 \text { sets of } 10 \text { with } \\
\text { a } 5 \text { second hold } \\
2 \times \text { per day }\end{array}$ \\
\hline $\begin{array}{l}\text { Scapular Y's while } \\
\text { standing facing a } \\
\text { wall }\end{array}$ & $\begin{array}{l}3 \text { sets of } 10 \\
\text { with a } 5 \\
\text { second hold } \\
2 \times \text { per day }\end{array}$ & $\begin{array}{l}3 \text { sets of } 10 \\
\text { with a } 5 \\
\text { second hold } \\
2 \times \text { per day }\end{array}$ & $\begin{array}{l}3 \text { sets of } 10 \\
\text { with a } 5 \\
\text { second hold } \\
2 \times \text { per day }\end{array}$ & $\begin{array}{l}3 \text { sets of } 10 \text { with } \\
\text { a } 5 \text { second hold } \\
2 \times \text { per day } \\
\text { Add } 2 \text { pound } \\
\text { weight }\end{array}$ & $\begin{array}{l}3 \text { sets of } 10 \\
\text { with a } 5 \\
\text { second hold } \\
2 \times \text { per day } \\
2 \text { pound } \\
\text { weight }\end{array}$ & $\begin{array}{l}3 \text { sets of } 10 \text { with } \\
\text { a } 5 \text { second hold } \\
2 \times \text { per day } \\
2 \text { pound weight }\end{array}$ & $\begin{array}{l}3 \text { sets of } 10 \text { with } \\
\text { a } 5 \text { second hold } \\
2 \times \text { per day } \\
2 \text { pound weight }\end{array}$ \\
\hline $\begin{array}{l}\text { GH internal rotation } \\
\text { and external rota- } \\
\text { tion in prone and } \\
\text { standing }\end{array}$ & $\begin{array}{l}2 \text { sets of } 10 \\
2 \times \text { per day }\end{array}$ & $\begin{array}{l}2 \text { sets of } 10 \\
2 \times \text { per day }\end{array}$ & $\begin{array}{l}2 \text { sets of } 10 \\
2 \times \text { per day }\end{array}$ & $\begin{array}{l}3 \text { sets of } 10 \\
2 \times \text { per day } \\
\text { Add } 1 \text { lbs. } \\
\text { weight }\end{array}$ & $\begin{array}{l}3 \text { sets of } 10 \\
2 \times \text { per day } \\
1 \mathrm{lbs} . \text { weight }\end{array}$ & $\begin{array}{l}3 \text { sets of } 10 \\
2 \times \text { per day }{ }^{* \wedge} \\
\text { Yellow resis- } \\
\text { tance band }\end{array}$ & $\begin{array}{l}3 \text { sets of } 10 \\
2 \times \text { per day }{ }^{* \wedge} \\
\text { Yellow resis- } \\
\text { tance band }\end{array}$ \\
\hline $\begin{array}{l}\text { Prone isometric } \\
\text { scapular Y's }\end{array}$ & Not given & $\begin{array}{l}1 \text { sets of } 10 \\
\text { with a } 5 \text { sec- } \\
\text { ond hold } \\
2 \times \text { per day }\end{array}$ & $\begin{array}{l}1 \text { sets of } 10 \\
\text { with a } 5 \\
\text { second hold } \\
2 \times \text { per day }\end{array}$ & $\begin{array}{l}1 \text { sets of } 10 \\
\text { with a } 5 \text { second } \\
\text { hold with } 1 \mathrm{lbs} \text {. } \\
\text { weight } * * * \\
2 \times \text { per day }\end{array}$ & $\begin{array}{l}1 \text { sets of } 10 \\
\text { with a } 5 \text { sec- } \\
\text { ond hold } \wedge \wedge \wedge \\
2 \times \text { per day }\end{array}$ & $\begin{array}{l}1 \text { sets of } 10 \text { with } \\
\text { a } 5 \text { second hold } \\
2 \times \text { per day }\end{array}$ & $\begin{array}{l}1 \text { sets of } 10 \text { with } \\
\text { a } 5 \text { second hold } \\
2 \times \text { per day }\end{array}$ \\
\hline $\begin{array}{l}\text { Scaption fly's with } \\
\text { elbow flexed to } 90^{\circ} \\
\text { in front of a mirror }\end{array}$ & Not given & $\begin{array}{l}1 \text { set of } 10^{\wedge \wedge} \\
2 \times \text { per day }\end{array}$ & $\begin{array}{l}1 \text { set of } 10^{\wedge \wedge} \\
2 \times \text { per day }\end{array}$ & $\begin{array}{l}1 \text { set of } 10^{\wedge \wedge} \\
2 \times \text { per day }\end{array}$ & $\begin{array}{l}1 \text { set of } 10^{\wedge \wedge} \\
2 \times \text { per day }\end{array}$ & $\begin{array}{l}1 \text { set of } 10^{\wedge} \\
2 \times \text { per day }\end{array}$ & $\begin{array}{l}1 \text { set of } 10^{\wedge \wedge} \\
2 \times \text { per day }\end{array}$ \\
\hline Wax on/Wax Off & Not given & Not given & Not given & Not given & $\begin{array}{l}30 \text { seconds } \\
\mathrm{CW} \\
30 \text { seconds } \\
\mathrm{CCW} \\
3 \text { sets through- } \\
\text { out the day }\end{array}$ & $\begin{array}{l}30 \text { seconds } \mathrm{CW} \\
30 \text { seconds } \\
\mathrm{CCW} \\
3 \text { sets through- } \\
\text { out the day }\end{array}$ & $\begin{array}{l}30 \text { seconds CW } \\
30 \text { seconds } \\
\text { CCW } \\
3 \text { sets through- } \\
\text { out the day }\end{array}$ \\
\hline
\end{tabular}

**On the second treatment session, patient reported performing this exercise with 30 -second holds instead of 5 second holds. Patient was reeducated to only perform for 5 second holds.

***Patient instructed to add extra thoracic extension to the isometric hold in order to address impaired thoracic extension mobility.

${ }^{\wedge}$ Patient was instructed to only continue this exercise until onset of pain or patient was unable to maintain scapular depression.

${ }^{\wedge \wedge}$ Patient reported increased pain from using weight, so weight was removed from HEP for this exercise.

${ }^{* \wedge}$ Exercise changed to standing ER/IR with resistance band tied to stable surface secondary to patient's reported difficulty with not having a stable surface to perform it on.

TA: Transversus Abdominis; DNF: Deep Neck Flexors; GH: Glenohumeral; CW: Clockwise; CCW: Counter-clockwise.

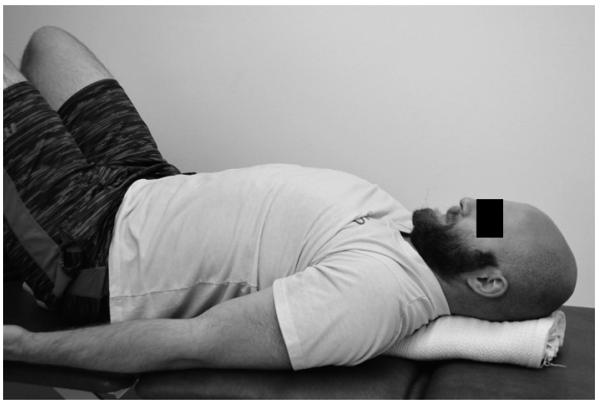

Fig. 1. Supine on towel roll with transversus abdominis (TA) and DNF activation, and scapular retraction.

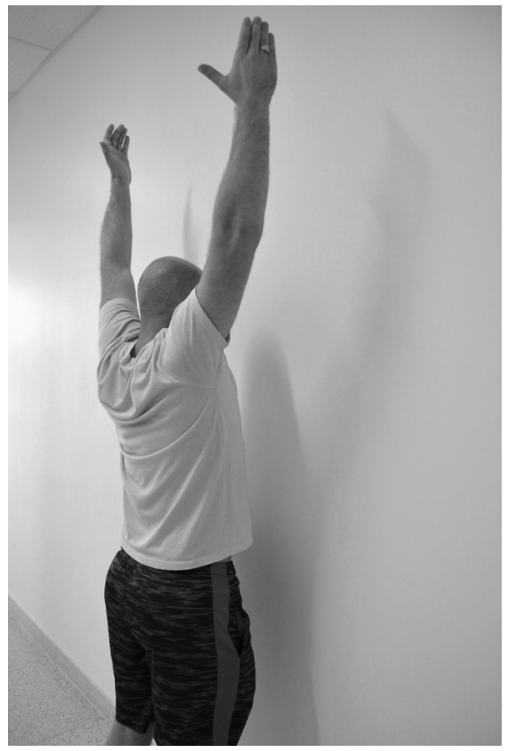

Fig. 2. Scapular standing facing a wall. Y's while. 


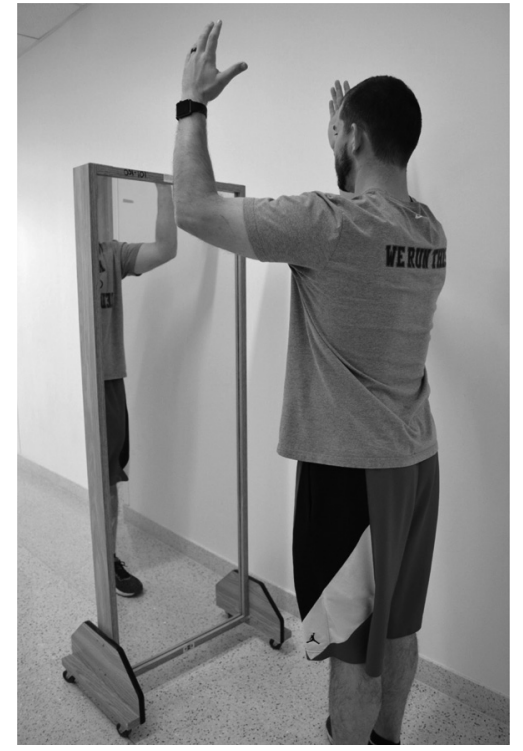

Fig. 3. Scaption fly's with elbow flexed to 90 degrees in front of a mirror.

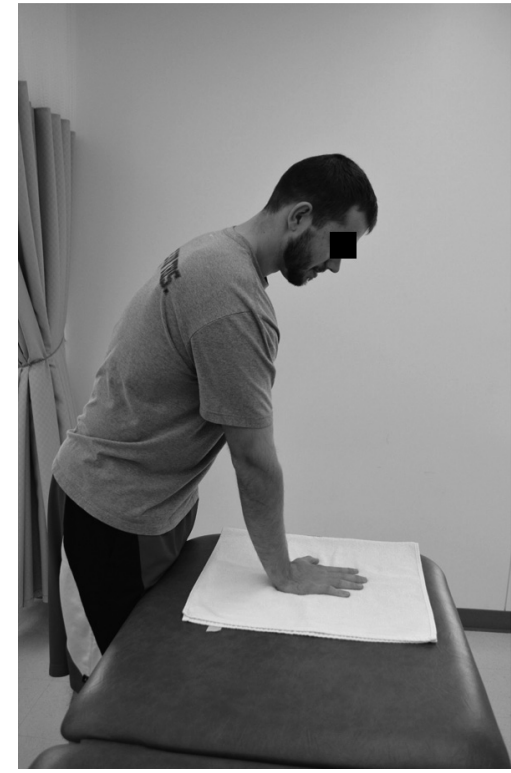

Fig. 4. Wax on/wax off.

1). The $15.2 \%$ represented a clinically significant change, obtaining the MCID range of $13.2 \%$ to $15.4 \% 24,26)$. The patient's overall score on the QuickDASH decreased from $61.0 \%$ at baseline to $29.5 \%$. This $31.5 \%$ reduction exceeds the MCID range by 2 to 3 times (MCID 9-11.3\%) $)^{30,31)}$.

The patient displayed improved posture as confirmed by reduced resting scapular abduction and Pm tightness, and two fold increase in DNF endurance (Table 2). His scapular upward rotation of 55 degrees was approaching the normal of 60 degrees $^{36)}$. The patient exhibited substantial gains in pain free active elevation of the right shoulder with AROM of flexion to 163 degrees and abduction to 168 degrees (Table 3). The patient through his strength gains in the GHJ elevators and scapular stabilizers was able to resist moderate to strong (4+/5) manual resistance with shoulder flexion and abduction (Table 4).

The patient expressed that he had elected to postpone his rTSR surgery, which was scheduled in about three weeks. He reported that his goals had been met for pain control and mobility of his arm. The goals of golfing and use of a mechanical drill had not been attempted. He was advised that he could gradually try these activities to determine his shoulder's tolerance. The patient reported that he no longer had pain on a daily bases or pain with his usual daily activities. He was able to sleep throughout the night without awakening due to pain. He had a self-assessed $95 \%$ improvement in overall shoulder function. Based on the patient's improved test and measures and self-reports, a three-month follow-up was recommended. In the interim, the patient was encouraged to continue daily with his prescribed HEP. The patient agreed to the recheck and acknowledge the importance of follow through with his HEP.

On the three months follow-up, the patient demonstrated maintained or improved test and measures and functional outcomes. He demonstrated compliance with his HEP and a good self-management strategy. Pain at worse on the NPRS, was now rated at 4/10 compared to previous levels of $8 / 10$, a twofold MCID $^{20}$. He denied any pain except when lifting heavy objects in an upright row position (GHJ 90 degrees abduction with IR). The patient shared a picture taken a few days prior to the follow-up of him repairing his house roof gutter with a mechanical drill. Due to his schedule, he still had not attempted to golf. The patient's goals of pain control, increase active mobility, and use of a mechanical drill had been met. The determination was made no additional follow-ups were indicated. He expressed his satisfaction with the prehab outcomes and that he had indefinitely postponed his rTSR.

\section{DISCUSSION}

The role of PT has been evolved from postoperative rehabilitation care to prehab management on several surgical populations. Recently, Paterson et al. reported a multimodal preoperative intervention including instruction was beneficial for patients opting for radical prostatectomy due to localized prostate cancer ${ }^{44)}$. Existing literature also suggests that preoperative inspiratory muscle training may prevent pulmonary complications and improve postsurgical outcome on esophageal cancer patients undergo esophageal resection ${ }^{45-47)}$. In a lumbar surgical population, a tailored made prehab program has been shown to reduce post-surgical pain, risk of avoidance behavior, worsening of psychological health and improves quality of life and functional activity levels ${ }^{48)}$.

PT prehab has been commonly applied on patients undergoing total hip and knee arthroplasty even though the evidence 
supporting the efficacy remains inconclusive $\left.{ }^{49}, 50\right)$. Wang et al. refuted the use of prehab finding it to have an early and small positive effect on pain and function, but did not improve cost, hospital length of stay, or quality of life ${ }^{51)}$. In contrast, Santa Mina et al. found the use of total body prehab improved the length of stay, pain, and function ${ }^{52}$. PT prehab, may also improve pre-surgical outcomes and influence patient expectations prior to surgery. Clode et al. reported a PT prehab program including exercise and education session twice weekly for eight weeks improved patients' pain and function before hip or knee arthroplasty and had a positive influence on patient expectations and higher satisfaction levels post-surgery ${ }^{49)}$.

There is support that a prehab program may defer the need for surgery. Holmgren et al. found in individuals with subacrominal impingement that a strengthening program to the rotator cuff and scapular stabilizers improved pain and function, thus reducing the need for subacrominal decompression surgery ${ }^{53)}$. In a 12-week total knee arthroplasty (TKA) prehab program, $19.4 \%$ of the participants elected to cancel surgery due to improved pain ${ }^{54)}$.

In this case report, completion of five weeks of PT prehab combined with excellent HEP compliance resulted in the patient obtaining his goals of pain control, increase active mobility, and regaining functional activities, which lead the patient to defer his rTSR. Although avoiding surgery was not an initial goal, the prehab program positively negated the need for surgery. The patient recognized the values of PT as a conservative option over the invasive surgical approach for his shoulder pain and dysfunction.

The primary limitation of this case study is that we only conducted one follow-up assessment three months after the PT prehab program concluded. Since the patient decided to postpone his rTSR surgery, we were not able to determine the effect of the PT prehab on the postsurgical outcomes. In addition, an assessment on patient's quality of life could have be recorded.

In summary, a five-week PT prehab program improved pre-operative test and measures on pain, joint mobility, muscle strength and function on a patient who had been scheduled for an rTSR surgery. The conservative PT approach delayed the need for surgery.

\section{Funding and Conflict of interest}

None.

\section{REFERENCES}

1) Arora RC, Brown $\mathrm{CH}$ 4th, Sanjanwala RM, et al.: "NEW" Prehabilitation: a 3-way approach to improve postoperative survival and health-related quality of life in cardiac surgery patients. Can J Cardiol, 2018, 34: 839-849. [Medline] [CrossRef]

2) Shanahan JL, Leissner KB: Prehabilitation for the enhanced recovery after surgery patient. J Laparoendosc Adv Surg Tech A, 2017, 27: 880-882. [Medline] [CrossRef]

3) Gometz A, Maislen D, Youtz C, et al.: The effectiveness of Prehabilitation (Prehab) in both functional and economic outcomes following spinal surgery: a systematic review. Cureus, 2018, 10: e2675. [Medline]

4) Marmelo F, Rocha V, Moreira-Gonçalves D: The impact of prehabilitation on post-surgical complications in patients undergoing non-urgent cardiovascular surgical intervention: systematic review and meta-analysis. Eur J Prev Cardiol, 2018, 25: 404-417. [Medline] [CrossRef]

5) Jensen BT, Lauridsen SV, Jensen JB: Prehabilitation for major abdominal urologic oncology surgery. Curr Opin Urol, 2018, 28: 243-250. [Medline] [CrossRef]

6) Boujibar F, Bonnevie T, Debeaumont D, et al.: Impact of prehabilitation on morbidity and mortality after pulmonary lobectomy by minimally invasive surgery: a cohort study. J Thorac Dis, 2018, 10: 2240-2248. [Medline] [CrossRef]

7) Gillis C, Fenton TR, Sajobi TT, et al.: Trimodal prehabilitation for colorectal surgery attenuates post-surgical losses in lean body mass: a pooled analysis of randomized controlled trials. Clin Nutr, 2019, 38: 1053-1060. [Medline] [CrossRef]

8) Santa Mina D, Hilton WJ, Matthew AG, et al.: Prehabilitation for radical prostatectomy: a multicentre randomized controlled trial. Surg Oncol, 2018, 27: 289-298. [Medline] [CrossRef]

9) Orange ST, Northgraves MJ, Marshall P, et al.: Exercise prehabilitation in elective intra-cavity surgery: a role within the ERAS pathway? A narrative review. Int J Surg, 2018, 56: 328-333. [Medline] [CrossRef]

10) Yang A, Sokolof J, Gulati A: The effect of preoperative exercise on upper extremity recovery following breast cancer surgery: a systematic review. Int J Rehabil Res, 2018, 41: 189-196. [Medline] [CrossRef]

11) Luther A, Gabriel J, Watson RP, et al.: The impact of total body Prehabilitation on post-operative outcomes after major abdominal surgery: a systematic review. World J Surg, 2018, 42: 2781-2791. [Medline] [CrossRef]

12) Chen H, Li S, Ruan T, et al.: Is it necessary to perform prehabilitation exercise for patients undergoing total knee arthroplasty: meta-analysis of randomized controlled trials. Phys Sportsmed, 2018, 46: 36-43. [Medline] [CrossRef]

13) Moyer R, Ikert K, Long K, et al.: The value of preoperative exercise and education for patients undergoing total hip and knee arthroplasty: a systematic review and meta-analysis. JBJS Rev, 2017, 5: e2. [Medline] [CrossRef]

14) Failla MJ, Logerstedt DS, Grindem H, et al.: Does extended preoperative rehabilitation influence outcomes 2 years after ACL reconstruction? A comparative effectiveness study between the MOON and Delaware-Oslo ACL cohorts. Am J Sports Med, 2016, 44: 2608-2614. [Medline] [CrossRef]

15) Cvetanovich GL, Frank RM, Chalmers PN, et al.: Surgical management of proximal humeral fractures: the emerging role of reverse total shoulder arthroplasty. Orthopedics, 2016, 39: e465-e473. [Medline] [CrossRef]

16) Kim SH, Wise BL, Zhang Y, et al.: Increasing incidence of shoulder arthroplasty in the United States. J Bone Joint Surg Am, 2011, 93: 2249-2254. [Medline] [CrossRef]

17) Schairer WW, Nwachukwu BU, Lyman S, et al.: National utilization of reverse total shoulder arthroplasty in the United States. J Shoulder Elbow Surg, 2015, 
24: 91-97. [Medline] [CrossRef]

18) Berliner JL, Regalado-Magdos A, Ma CB, et al.: Biomechanics of reverse total shoulder arthroplasty. J Shoulder Elbow Surg, 2015, 24: 150-160. [Medline] [CrossRef]

19) Ferraz MB, Quaresma MR, Aquino LR, et al.: Reliability of pain scales in the assessment of literate and illiterate patients with rheumatoid arthritis. J Rheumatol, 1990, 17: 1022-1024. [Medline]

20) Michener LA, Snyder AR, Leggin BG: Responsiveness of the numeric pain rating scale in patients with shoulder pain and the effect of surgical status. J Sport Rehabil, 2011, 20: 115-128. [Medline] [CrossRef]

21) Chester R, Jerosch-Herold C, Lewis J, et al.: The SPADI and QuickDASH are similarly responsive in patients undergoing physical therapy for shoulder pain. J Orthop Sports Phys Ther, 2017, 47: 538-547. [Medline] [CrossRef]

22) Breckenridge JD, McAuley JH: Shoulder Pain and Disability Index (SPADI). J Physiother, 2011, 57: 197. [Medline] [CrossRef]

23) Roy JS, MacDermid JC, Woodhouse LJ: Measuring shoulder function: a systematic review of four questionnaires. Arthritis Rheum, 2009, 61: 623-632. [Medline] [CrossRef]

24) Schmitt JS, Di Fabio RP: Reliable change and minimum important difference (MID) proportions facilitated group responsiveness comparisons using individual threshold criteria. J Clin Epidemiol, 2004, 57: 1008-1018. [Medline] [CrossRef]

25) Roddey TS, Olson SL, Cook KF, et al.: Comparison of the University of California-Los Angeles Shoulder Scale and the Simple Shoulder Test with the shoulder pain and disability index: single-administration reliability and validity. Phys Ther, 2000, 80: 759-768. [Medline]

26) Tveitå EK, Ekeberg OM, Juel NG, et al.: Responsiveness of the shoulder pain and disability index in patients with adhesive capsulitis. BMC Musculoskelet Disord, 2008, 9: 161. [Medline] [CrossRef]

27) Aasheim T, Finsen V: The DASH and the QuickDASH instruments. Normative values in the general population in Norway. J Hand Surg Eur Vol, 2014, 39: 140-144. [Medline] [CrossRef]

28) Beaton DE, Wright JG, Katz JN, Upper Extremity Collaborative Group: Development of the QuickDASH: comparison of three item-reduction approaches. J Bone Joint Surg Am, 2005, 87: 1038-1046. [Medline]

29) Fayad F, Lefevre-Colau MM, Gautheron V, et al.: Reliability, validity and responsiveness of the French version of the questionnaire Quick Disability of the Arm, Shoulder and Hand in shoulder disorders. Man Ther, 2009, 14: 206-212. [Medline] [CrossRef]

30) Polson K, Reid D, McNair PJ, et al.: Responsiveness, minimal importance difference and minimal detectable change scores of the shortened disability arm shoulder hand (QuickDASH) questionnaire. Man Ther, 2010, 15: 404-407. [Medline] [CrossRef]

31) Gabel CP, Yelland M, Melloh M, et al.: A modified QuickDASH-9 provides a valid outcome instrument for upper limb function. BMC Musculoskelet Disord, 2009, 10: 161. [Medline] [CrossRef]

32) Magee DJ: Orthopedic physical assessment 5th ed. Philadelphia: Saunders, 2007, pp 130-202.

33) Lewis JS, Valentine RE: The pectoralis minor length test: a study of the intra-rater reliability and diagnostic accuracy in subjects with and without shoulder symptoms. BMC Musculoskelet Disord, 2007, 8: 64. [Medline] [CrossRef]

34) Domenech MA, Sizer PS, Dedrick GS, et al.: The deep neck flexor endurance test: normative data scores in healthy adults. PM R, 2011, 3: 105-110. [Medline] [CrossRef]

35) Norkin CC, White DJ: Measurement of joint motion: a guide to goniometry, 5th ed. Philadelphia: F.A. Davis Company, 2017.

36) Sahrmann SA: Diagnosis and treatment of movement impairment syndromes. Maryland Heights: Mosby, 2002, pp $193-261$.

37) Kendall FP: Muscles: testing and function with posture and pain, 5th ed. Philadelphia: Lippincott Williams \& Wilkins, 2005.

38) Wolf EM, Agrawal V: Transdeltoid palpation (the rent test) in the diagnosis of rotator cuff tears. J Shoulder Elbow Surg, 2001, 10: 470-473. [Medline] [CrossRef]

39) Park HB, Yokota A, Gill HS, et al.: Diagnostic accuracy of clinical tests for the different degrees of subacromial impingement syndrome. J Bone Joint Surg Am, 2005, 87: 1446-1455. [Medline]

40) Reiman M: Orthopedic Clinical Examination. Champaign: Human Kinetics, 2016.

41) Kim SH, Ha KI, Han KY: Biceps load test: a clinical test for superior labrum anterior and posterior lesions in shoulders with recurrent anterior dislocations. Am J Sports Med, 1999, 27: 300-303. [Medline] [CrossRef]

42) Lim JY, Lee JS, Mun BM, et al.: A comparison of trapezius muscle activities of different shoulder abduction angles and rotation conditions during prone horizontal abduction. J Phys Ther Sci, 2015, 27: 97-100. [Medline] [CrossRef]

43) Peek AL, Miller C, Heneghan NR: Thoracic manual therapy in the management of non-specific shoulder pain: a systematic review. J Manual Manip Ther, 2015, 23: 176-187. [Medline] [CrossRef]

44) Paterson C, Primeau C, Pullar I, et al.: Development of a Prehabilitation multimodal supportive care interventions for men and their partners before radical prostatectomy for localized prostate cancer. Cancer Nurs, 2019, 42: E47-E53. [Medline] [CrossRef]

45) Findlay JM, Gillies RS, Millo J, et al.: Enhanced recovery for esophagectomy: a systematic review and evidence-based guidelines. Ann Surg, 2014, 259: 413-431. [Medline] [CrossRef]

46) Guinan EM, Dowds J, Donohoe C, et al.: The physiotherapist and the esophageal cancer patient: from prehabilitation to rehabilitation. Dis Esophagus, 2017, 30: 1-12. [Medline]

47) Valkenet K, Trappenburg JC, Gosselink R, et al.: Preoperative inspiratory muscle training to prevent postoperative pulmonary complications in patients undergoing esophageal resection (PREPARE study): study protocol for a randomized controlled trial. Trials, 2014, 15: 144. [Medline] [CrossRef]

48) Lindbäck Y, Tropp H, Enthoven P, et al.: PREPARE: presurgery physiotherapy for patients with degenerative lumbar spine disorder: a randomized controlled trial. Spine J, 2018, 18: 1347-1355. [Medline] [CrossRef]

49) Clode NJ, Perry MA, Wulff L: Does physiotherapy prehabilitation improve pre-surgical outcomes and influence patient expectations prior to knee and hip joint arthroplasty? Int J Orthop Trauma Nurs, 2018, 30: 14-19. [Medline] [CrossRef]

50) Mat Eil Ismail MS, Sharifudin MA, Shokri AA, et al.: Preoperative physiotherapy and short-term functional outcomes of primary total knee arthroplasty. Singapore Med J, 2016, 57: 138-143. [Medline] [CrossRef]

51) Wang L, LeE M, Zhang Z, et al.: Does preoperative rehabilitation for patients planning to undergo joint replacement surgery improve outcomes? A systematic 
review and meta-analysis of randomised controlled trials. BMJ Open, 2016, 6: e009857. [Medline] [CrossRef]

52) Santa Mina D, Clarke H, Ritvo P, et al.: Effect of total-body prehabilitation on postoperative outcomes: a systematic review and meta-analysis. Physiotherapy, 2014, 100: 196-207. [Medline] [CrossRef]

53) Holmgren T, Hallgren HB, Oberg B, et al.: Effect of specific exercise strategy on need for surgery in patients with subacromial impingement syndrome: randomised controlled study. Br J Sports Med, 2014, 48: 1456-1457. [Medline] [CrossRef]

54) Aytekin E, Sukur E, Oz N, et al.: The effect of a 12 week prehabilitation program on pain and function for patients undergoing total knee arthroplasty: a prospective controlled study. J Clin Orthop Trauma, 2019, 10: 345-349. [Medline] [CrossRef] 